The Effects of Age and Delay on Responses to Repeated Questions in Forensic Interviews With Children Alleging Sexual Abuse

Samantha J Andrews and Michael E Lamb

University of Cambridge

This article may not exactly replicate the final version published in the APA journal. It is not the copy of record.

Andrews, S. J., \& Lamb, M. E. (2013, December 16). The Effects of Age and Delay on Responses to Repeated Questions in Forensic Interviews With Children Alleging Sexual Abuse. Law and Human Behavior. Advance online publication. doi: 10.1037/1hb0000064

Corresponding Author: Michael E. Lamb, Department of Psychology, University of Cambridge, Free School Lane, Cambridge CB2 3RQ, U.K. Email: mel37@cam.ac.uk 


\begin{abstract}
We examined transcripts of forensic interviews with 115 children aged between 3 and 12 years, interviewed between 1 day and 18 months after allegedly experiencing a single incident of sexual abuse. Repeated questions were categorized with respect to the reasons why interviewers asked questions again, how interviewers asked repeated questions, and how children responded. On average, interviewers asked 3 repeated questions per interview. As age increased, the frequency of question repetition declined but there was no association between repetition and delay. Interviewers most often repeated questions for clarification (53.1\%), but questions were also repeated frequently to challenge children's previous responses (23.7\%), and for no apparent reason (20.1\%). In response, children typically repeated $(54.1 \%)$ or elaborated on $(31.5 \%)$ their previous answers; they contradicted themselves less often (10.8\%). Questions repeated using suggestive prompts were more likely to elicit contradictions. There was no association between age or delay and the reasons why questions were repeated, how they were repeated, and how children responded. These findings emphasize the importance of training forensic interviewers to repeat questions only when the children or interviewers seek clarification and to encourage children who are anxious or reluctant to disclose. All repeated questions should be open-ended and interviewers should explain to children why questions are being repeated.
\end{abstract}


The Effects of Age and Delay on Responses to Repeated Questions in Forensic Interviews with Children Alleging Sexual Abuse

The primary aim of forensic interviews with alleged victims of abuse is to obtain truthful, consistent and accurate accounts that are admissible in court and can advance the investigative process (American Professional Society on the Abuse of Children (APSAC), 2012; Home Office 2011, section 3.1; Lamb, Hershkowitz, Orbach \& Esplin, 2008). Contradictory or nonsensical responses may reduce children's testimonial credibility (Home Office 2011, section 2.214; Semmler \& Brewer, 2002), so interviewers are encouraged to avoid techniques that might undermine children's consistency. The repetition of closed-ended questions has been identified as a practice likely to produce inconsistent responding, although there has been little research on question repetition in forensic contexts. In the present study, we thus explored whether age and the delay between the to-be-remembered event and the forensic interview were associated with the frequency of repeated questions and how children responded.

\section{Repeated Questions}

Child forensic interviewers may often repeat questions to make the request clear, to clarify details previously mentioned by the children (e.g., ambiguous or unclear responses), or to encourage children who are anxious or reluctant to disclose (La Rooy \& Lamb, 2011). However, repeated closed-ended questions are sometimes considered problematic on the grounds that children may change details in their accounts and thus respond inconsistently (Lamb \& Fauchier, 2001; Zajac, Gross \& Hayne, 2003), believing that interviewers are unsatisfied with their initial answers or that their initial answers were incorrect (Howie, Kurukulasuriya, Nash \& Marsh, 2009; Howie, Nash, Kurukulasuriya \& Bowman, 2012; Melinder, Scullin, Gravvold \& Iversen, 2007). 
Despite these concerns, interview guidelines often fail to provide detailed guidance concerning the appropriate use of repeated questions (e.g., Anderson, Ellefson, Lashley, Miller, Olinger, Russell, Stauffer \& Weigman, 2010; Lamb et al., 2008), and even though some protocols counsel against question repetition, explicitly discourage the repetition of closed-ended questions, and encourage interviewers to explain why some questions were repeated (e.g., Home Office, 2011), questions appear to be repeated in many forensic interviews (La Rooy \& Lamb, 2011). There has been very little field research addressing the potential problems associated with repeated questioning in real forensic interviews. However, the effects of question repetition are well established in the experimental literature. The next four sections discuss findings from laboratory experiments.

\section{Closed-ended and Suggestive Repeated Questions}

Research conducted in experimental settings shows that children frequently modify their answers when questions are repeated suggestively (for reviews see Ceci \& Bruck, 1995; Ceci \& Friedman, 2000; Lyon, 2002). For example, Howie et al. (2012) found that 4-, 6-, and 8-year-old children were sensitive to adult dissatisfaction, interpreting repeated questions as implicit suggestions to change their answers. Endres, Poggenpohl and Erben (1999) reported that 5- and 6-year-old children were misled more than 50\% of the time when questions were repeated, particularly when interviewers used closed-ended suggestive follow-up prompts to challenge the children's previous answers (e.g., “Are you sure about that?”). Experimental and analogue studies also indicate that children may contradict their answers when closedended questions are repeated. For example, children appear especially likely to provide inconsistent and inaccurate information to repeated closed-ended questions when asked about experienced events (Poole \& White, 1991), including innocuous touches (Quas, Davis, Goodman \& Myers, 2007) or videos they have observed (Scullin \& Ceci, 2001). However, Lyon, Malloy, Quas and Talwar (2008) reported few inconsistencies in responses to repeated 
yes/no prompts when children promised to tell the truth. In light of this finding, more research is needed about the effects of repeated closed-ended questions in real forensic interviews where there is a strong emphasis on telling the truth.

\section{Open-ended Repeated Questions}

Repeated questions do not necessarily degrade the accuracy of children's accounts. It is well recognized that open-ended questions elicit more detailed and accurate responses from children than focused questions (Jones \& Pipe, 2002; Lamb, La Rooy, Malloy \& Katz, 2011; Pipe, Lamb, Orbach \& Esplin, 2004) and that continued open-ended questioning can increase the amount of information children report from free-recall memory (see Lamb et al., 2008, for a review). Successive accounts of the same incident often contain new information, a phenomenon known as reminiscence (Erdelyi, 1996), and it has been claimed that repeated open-ended questioning enhances memory retrieval through practice and redintegration (Baddeley, 2007). Poole and White (1991) thus found that, when children were asked openended prompts a second time, they provided additional accurate information that was not reported earlier. Similarly, Memon and Vartoukian (1996) found that 5- and 7-year-old children questioned about a staged event were more accurate and recalled more correct details when prompted a second time using open-ended repeated questions rather than closedended repeated questions.

Age

Laboratory research shows that younger children are more likely than older children and adults to be detrimentally affected by repeated questioning within interviews. For example, Warren, Hulse-Trotter and Tubbs (1991) reported that children were more likely than adults to change their responses to open- and closed-ended repeated questions when interviewers responded negatively to their initial answers. Krähenbühl, Blades and Eiser (2009) showed that the accuracy and consistency of 4- to 9-year-old children's responses to 
closed-ended repeated questions increased with age, although multiple repetitions of unanswerable questions continued to have a detrimental effect at all ages. Howie et al. (2012) similarly found that 4- and 6-year-old children were more likely than 8-year-olds to change their initial answers in response to close-ended repeated questions even though these younger children were less likely to interpret question repetition as an implicit request to change their answers.

\section{Delay}

Surprisingly, researchers have not yet studied the effects of delay and the dynamics of repeated questions directly. Understanding the effects of delay on children's responses to question repetition is important, since children often experience varying degrees of delay between the to-be-remembered events and forensic interviews about them. To our knowledge, only Poole and White (1993) have examined the effects of delay and repeated questioning. They found that, after a 2-year delay, children were more likely to speculate inappropriately and gave less consistent responses to unanswerable questions than they did initially, perhaps because memory traces had become weaker over time.

\section{Field Research}

Considerable controversy exists concerning the effects of question repetition when children are questioned about personally significant and emotionally salient events by forensic interviewers. The controversy has persisted due to the lack of research on repeated questions in real forensic interviews.

The difficulties associated with analyzing repeated questions in real forensic interviews may explain why so few studies have been conducted (La Rooy \& Lamb, 2011). Experimental research allows repeated questions and children's responses to be examined systematically (e.g., Howie, Sheehan, Mojarrad \& Wrzesinska, 2004). However, each forensic interview is unique and interviewers seldom repeat questions word-for-word. For 
example, two questions may seek different details about the same topic (e.g., "Did you see him hurt your brother?" is not the same as "How do you think he hurt your brother?") and question repetition must be viewed in the context of the whole interview, because identical questions may not in fact prompt for the same details (e.g., Interviewer: "How did he [the suspect] make you?" Child: "He didn't make me. My daddy did". Interviewer: "How did he [the father] make you?").

The only field study to examine repeated questions in real forensic interviews found that 37 alleged victims of abuse most often repeated (54\%) or elaborated $(27 \%)$ on their previous responses to repeated questions, and contradicted their answers only $7 \%$ of the time, even though $62 \%$ of the questions were repeated to challenge the children's previous responses (La Rooy \& Lamb, 2011). These findings suggest that question repetition may not affect the consistency of children's responses as much in the field as in the experimental laboratory, perhaps because the repetition of questions about emotionally salient events does not have the same effects as question repetition about less personally significant events. However, La Rooy and Lamb (2011) did not distinguish between open- and closed-ended repeated questions and, as noted above, this is an essential consideration when interpreting inconsistencies in children's responses.

\section{Present Study}

The current study was designed to investigate question repetition in forensic interviews of children. Specifically, age and delay were examined in relation to a) the number of times children were asked repeated questions within a single interview session, b) why questions were repeated, c) how interviewers asked repeated questions and d) how the children responded. It was predicted that closed and suggestive prompts would be more likely than open-ended prompts to elicit contradictions from children, and that these effects would 
be more detrimental for younger children and those who experienced longer delays than for older children and those who experienced shorter delays.

\section{Method}

\section{Sample}

One hundred and fifteen alleged victims of child sexual abuse who ranged in age from 3 to 12 years were included in the study. Transcripts of interviews with the children had been included in an earlier study of the effects of age and delay on the informativeness of alleged sex abuse victims (Lamb, Sternberg \& Esplin, 2000), for which participants were selected from thousands of archived interviews to create a sample comprising children of varying ages (3.8 - 12.5 years, $M=7.3$ years, $S D=2.4)$ who had experienced varying degrees of delay between incident and interview (1 day - 18 months) and were being interviewed formally for the first time.

Children reported sexually abusive experiences involving penetration $(n=39)$, touching under clothes $(n=38)$, touching over clothes $(n=18)$ and indecent exposure $(n=$ 3). In 17 interviews, it was unclear whether the children were touched over or under their clothes. The interviews were conducted by at least 25 different trained forensic investigators at a large facility in the South-Western United States between 1986 and 1994. At the time, there were no local guidelines for investigative interviewing and interviewers did not systematically explain the 'ground rules' to interviewees. We thus expected that questions might be repeated more frequently than they would be in contemporary interviews.

The final sample included 23 boys and 92 girls who could be categorized definitively into 3 age (less than 6 years, 6 to 9 years, more than 9 years) and 2 delay (less than 1 month, 1 month and over) conditions. Table 1 depicts the distribution of the sample across age $\mathrm{x}$ delay conditions. Based on interview center files, the children's accounts, and accounts from 
collateral witnesses, all interviewees appeared to have been abused only once. None of the children had been previously interviewed about this or any other abusive event. In $96 \%$ ( $n=$ 110) of the cases the alleged abusers were known to the children.

\section{Coding of Transcripts}

The interviews had been transcribed and checked for the initial study by Lamb et al. (2000) before being further coded as described below.

\section{Identifying repeated questions.}

Only the substantive phases of the interviews were examined. The substantive phase refers to the portion of the interview in which the incident under investigation was discussed. After initial rapport-building, this phase could be introduced with an open-ended prompt such as "Why have you come here today?" and ended when the child had no more forensically relevant information to provide. Questions that were repeated in the non-substantive phases of the interview, such as the rapport building and closure phases, were not included in the present study.

Repeated questions were operationally defined as interviewer prompts or utterances that refocused the children on their previous responses and were designed to elicit further information. They were either repeated verbatim $(19.8 \%)$ or had been reworded $(80.2 \%)$. Questions were not considered to be repeated when the interviewers were clearly seeking information different from that sought in their initial prompt (e.g., Interviewer: "How did he [the suspect] touch you?" Child: "He didn't touch me that time, my friend did." Interviewer: "How did he [the friend] touch you?"), were probing for more specific information about a topic (e.g., Interviewer: "Did he touch you?" Child: "Yes.” Interviewer: "How did he touch you?”; Interviewer: “How did he hurt J.?” Child: “I don’t know.” Interviewer: “Did you see him hurt J.?" Child "No.” Interviewer: "How do you think he hurt J.?”), or repeated a question because the child interpreted the initial question too literally (e.g., Interviewer: "Can 
you tell me how it came out of his jeans?" Child: "Yes." Interviewer: "How did it come out of his jeans?"). Questions were also not coded as repeated when the child did not answer the initial prompt because such instances do not provide children with the opportunity to change their first response. Questions were most often repeated immediately after the initial responses $(62.8 \%)$, but were sometimes repeated later in the interview $(37.2 \%)$.

\section{Why were children asked repeated questions?}

After repeated questions were identified, the reasons for repetition were categorized using an expanded version of La Rooy and Lamb's (2011) coding scheme. Examples for each code are provided in Table 2.

1. No apparent reason. The child replied in a clear and unequivocal manner but the interviewer repeated the question nonetheless. It was not obvious that the interviewers were challenging the truthfulness or the accuracy of the children's previous responses, or asking the children to clarify their previous responses.

2. Challenge. The interviewer explicitly cast doubt on the truthfulness and/or the accuracy of the child's previous response and prompted her/him to answer the question again.

3. Child clarification. The interviewer repeated a question because the child did not understand and/or asked for clarification. Note that, as shown in Table 2, the children provided forensically relevant details to the first response and were given the opportunity to change their previous responses when the questions were repeated.

4. Interviewer clarification. The interviewer repeated a question because s/he did not understand, hear and/or asked for clarification. Questions repeated for reasons of interviewer clarification were not coded by La Rooy and Lamb (2011). However, because these questions refocused children on their previous responses and provided them with opportunities to change their answers, they were included in the present study. Note that, as shown in Table 2, the interviewers did not explicitly cast doubt on the truthfulness and/or the accuracy of the 
children's initial responses with repeated questions of this sort, and were thus distinct from questions repeated to challenge children.

5. Digression. The child responded but was off task, resistant or provided an irrelevant response to the target question. For repeated questions to be coded as digressions the child must have provided forensically relevant details in the initial response, so that when the question was repeated, s/he had the opportunity to change that information.

6. Compound. When the interviewer prompted the child for several pieces of information in a single utterance and/or the child did not respond with all the details the interviewer asked for.

\section{What prompts did interviewers use to repeat questions?}

After repeated questions had been identified and the reasons why they were repeated had been coded, the types of interviewer utterances used to refocus the children were categorized. The transcripts had been previously coded by Lamb et al. (2000) using 13 categories to differentiate among interviewer utterances. However, only 4 utterance classifications were relevant in the context of this study. Examples for each code are provided in Table 3.

1. Invitations. Open-ended, input-free utterances used to elicit free-recall responses from children. Such questions, statements, imperatives or contextual cues do not restrict the child's focus except in a general sense. Invitations can also follow-up on information just disclosed, or cue for additional free-recall elaboration about details previously disclosed.

2. Directive prompts. Open-ended questions that refocus the child on aspects or details of the allegation which they have previously mentioned, mostly using 'WH' utterances to request further information.

3. Option-posing prompts. Closed-ended questions that refocus the child's attention on details of the allegation which they have not previously mentioned, though without 
implying an expected response. They can be formulated as 'yes/no' questions or 'choice' questions.

4. Suggestive prompts. Closed-ended statements or questions formulated in a way which communicates the expected response. They may introduce information not disclosed by the child but assumed by the interviewer or query the truthfulness of the child's response.

\section{How did children respond to repeated questions?}

A modified version of La Rooy and Lamb's (2011) coding scheme was used to identify how the children responded to repeated questions, with three additional categories included to ensure that children's responses could be exhaustively categorized. Examples for each code are provided in Table 4.

1. Elaboration. The child expanded on a previous response by providing additional forensically relevant information.

2. Repetition. The child responded by reporting the same information.

3. Contradiction. The child negated what s/he had previously reported or provided conflicting information.

4. Digression. The child responded but was off task, resistant or provided an irrelevant response.

5. No answer. The child was not responsive.

6. Question. The child responded by asking the interviewer a question and the interviewer changed the subsequent line of questioning. No such responses were found in the present study.

\section{Inter-rater Reliability}

Inter-rater reliability in classification of the interviewer utterances was reported by Lamb et al. (2000) to be $83 \%$ - with disagreements resolved by discussion. Two new raters independently identified and coded repeated questions in a random selection of $20 \%$ of the 
transcripts that had been re-coded for the present study. Agreement with respect to the identification of repeated questions was $89 \%$ (agreements/total number of repeated questions identified). Agreement among the three raters coding the reasons why questions were repeated, assessed using Fleiss' kappa, was substantial (see Landis \& Koch, 1977), $K=0.75$ $(S E=0.025), 95 \% \mathrm{CI}[.70, .80]$, as was the agreement when coding the children's responses, $K=0.71(S E=0.036), 95 \%$ CI $[.64, .78]$.

\section{Results}

\section{How Many Times were Questions Repeated?}

On average, $68.03(S D=25.10)$ interviewer prompts were identified in each interview, with $2.90(S D=2.02)$ or $4.3 \%$ repeated once. The number of questions repeated in each interview ranged from 0 to 9 , though fewer than six repeated questions were asked in the majority of interviews $(85.7 \%)$. Interviewers provided children with the opportunity to change their previous responses by repeating questions in $105(90.4 \%)$ of the interviews.

A multiple regression analysis was conducted to determine whether age (in years) and delay (less than 1 month, 1 month and over) were associated with the frequency with which questions were repeated. Only age (standardized $\beta=-.38, p<.001,95 \%$ CI $[-.93,-.35]$ ) significantly predicted the frequency with which questions were repeated, adjusted $R^{2}=.14$, $F(2,114)=10.24, p<.001,95 \%$ CI $[6.93,13.22]$, explaining $13.9 \%$ of the variance. Younger children were asked significantly more repeated questions than older children.

There were no main or interaction effects for age or delay evident in any other analyses. Age and delay were therefore not included in any of the analyses reported below.

\section{Why were Children Asked Repeated Questions?}


The analyses below focus on 333 questions that were repeated only once. Ten children were not included in the following analyses because they were not asked a repeated question.

Proportion scores were calculated to control for the total number of repeated questions each child was asked. Questions were repeated because clarification was sought either by the interviewer $(M=0.37 ; S D=0.35 ; 38.7 \%)$ or the child $(M=0.14 ; S D=0.22$; $14.4 \%)$. Additionally, questions were repeated to challenge children's previous responses ( $M$ $=0.23 ; S D=0.31 ; 23.7 \%)$ or for no apparent reason $(M=0.23 ; S D=0.32 ; 20.1 \%)$. Interviewers also repeated questions because the child digressed $(M=0.02 ; S D=0.08$; $2.1 \%)$, or a compound question had been asked $(M=0.007 ; S D=0.042 ; 0.9 \%)$.

\section{What Prompts did Interviewers use to Repeat Questions?}

Repeated questions involved closed-ended option-posing $(M=0.62 ; S D=0.33$; $61.3 \%)$ and suggestive $(M=0.08 ; S D=0.19 ; 8.4 \%)$ prompts, and open-ended invitations $(M$ $=0.04 ; S D=0.13 ; 5.4 \%)$ and directive $(M=0.25 ; S D=0.29 ; 24.9 \%)$ prompts.

\section{How did Children Respond to Repeated Questions?}

Children responded to repeated questions by repeating their previous responses $(M=$ $0.56 ; S D=0.33 ; 54.1 \%)$, elaborating on their answers $(M=0.28 ; S D=0.31 ; 31.5 \%)$ or contradicting themselves $(M=0.13 ; S D=0.25 ; 10.8 \%)$. Children also responded by digressing $(M=0.009 ; S D=0.059 ; 1.2 \%)$ or not responding $(M=0.019 ; S D=0.071 ; 2.4 \%)$. None of the children responded by asking the interviewer a question.

\section{Types of Prompts used as a Function of the Reasons for Repetition}

Table 5 depicts the results of a chi-square test showing a significant interaction between reasons for repeating questions and the types of prompt used to repeat questions, $\left.\chi^{2}(9, N=323)=54.49, p=<.001\right), V=.24$, when reasons for repeating questions categorized as digression $(n=7)$ and compound $(n=3)$ were excluded to avoid violating the 
distributional assumptions of chi-square tests. Questions repeated to challenge children were significantly more likely to be suggestive prompts and significantly less likely to be directive prompts. When children needed clarification, interviewers were more likely to use invitations when repeating the questions than any other type of prompt. When interviewers needed clarification they were more likely to use directive prompts and less likely to use suggestive prompts.

\section{Children's Responses as a Function of the Reasons for Repetition}

Table 6 depicts the results of a separate chi-square test showing a significant interaction between reasons for repeating questions and the types of responses elicited, $\chi^{2}(6$, $N=312)=73.78, p=<.001), V=.34$, when reasons for repeating questions categorized as digression $(n=7)$ or compound $(n=3)$, and responses categorized as digression $(n=4)$ and no answer $(n=8)$ were excluded to avoid violating the distributional assumptions of chisquare tests. Those who were refocused on their previous responses for no apparent reason were significantly more likely to repeat their answers rather than elaborate upon them. Children who were challenged were also less likely to elaborate on their previous responses. Not surprisingly, children who asked for clarification were more likely to elaborate upon their answers and less likely to repeat themselves.

\section{Children's Responses as a Function of the Types of Prompt}

Table 7 depicts the results of a separate chi-square test showing a significant interaction between the types of prompt used to repeat questions and the types of responses elicited, $\left.\chi^{2}(6, N=321)=41.21, p=<.001\right), V=.25$, when responses categorized as digression $(n=4)$ and no answer $(n=8)$ were excluded to avoid violating the distributional assumptions of chi-square tests. Children were significantly more likely to elaborate upon their answers when questions were repeated using directive prompts and were significantly less likely to elaborate when the prompts were option-posing. Conversely, children were 
significantly more likely to repeat their responses when questions were repeated using option-posing prompts and were less likely to repeat their responses when questions were repeated using directive prompts. Contradictions were more likely to be elicited by suggestive prompts than any other question type.

\section{Discussion}

This study was the first to examine the effects of age and delay on children's responses to repeated questions in real forensic interviews. We aimed to compare the use and effects of open-ended and closed-ended prompts on children's responses in order to determine whether question repetition had the same adverse effects on children's consistency as question repetition in laboratory analogue contexts. We also assessed the frequency of question repetition in child forensic interviews and explored previously unanswered questions concerning the effects of age and delay in relation to the reasons why questions were repeated, the types of prompts interviewers used to repeat questions, and how children responded. Understanding the dynamics of repeated questions in forensic interviews is an important concern for both practitioners and researchers, because most interview guidelines fail to provide detailed guidance concerning the appropriate use of repeated questions (e.g., Anderson et al., 2010; Lamb et al., 2008). Because questions are repeated in most forensic interviews, it is vital to understand when and what kinds of questions can be repeated safely.

\section{Key Findings}

Children were asked repeated questions in all but ten of the interviews, with $4.3 \%$ of the substantive interviewer prompts being repeated on average. This result is consistent with previous studies showing that questions are regularly repeated in forensic interviews (La Rooy \& Lamb, 2011; Warren, Garven, Walker \& Woodall, 2000). 
Questions were most often repeated using closed-ended prompts (option-posing and suggestive, 69.7\%) rather than open-ended prompts (invitations and directives, $30.3 \%$ ). Overall, open-ended prompts were more likely to be used when questions were repeated for purposes of child and interviewer clarification, whereas closed-ended prompts were more likely to challenge children's previous responses. This form of questioning may place pressure on children to reconsider and change their previous responses. Indeed, suggestive repeated questions were significantly more likely to elicit contradictions than any other type of prompt. Compared to suggestive and invitation prompts, directive prompts were more likely to elicit elaboration and option-posing prompts were less likely to elicit elaboration, whereas, compared to invitation and suggestive prompts, option-posing prompts were more likely to elicit repetition and directive prompts were less likely to elicit repetition. Furthermore, when questions were repeated for no apparent reason children were more likely to repeat their answers than elaborate or contradict. When children were challenged they were also less likely to elaborate than to repeat or contradict. On the other hand, when questions were repeated because the children requested clarification, children were more likely to elaborate on and less likely to repeat their previous responses than to contradict them. Interestingly, interviewer requests for clarification resulted in almost as many contradictions as questions repeated to challenge children. Although interviewers should not be discouraged from repeating open-ended questions so that they are able to clarify information, interviewers in the present study did not routinely explain to children why questions were being repeated. Children might have interpreted such requests for clarification as an indication that their previous response was unsatisfactory.

Our results support previous research in experimental contexts suggesting that children are more likely to change their answers when questioned repeatedly using closedended suggestive prompts (e.g., Endres et al., 1999; Quas et al., 2007; Scullin \& Ceci, 2001). 
However, the rate of inconsistent responding when children were prompted using closedended questions was lower in the present study (13.2\%) than in many laboratory experiments (e.g., Endres et al., 1999, 70\%; Howie et al., 2009, 10-36\%; Lyon et al., 2008, 4\%). Perhaps this is because experimental studies involve simple scripted closed-ended questions that are repeated word-for-word whereas the questions repeated in real forensic interviews occur in the context of dynamic and unpredictable interactions. This makes it problematic to assess the effects of question repetition in vacuo (Gilstrap \& Ceci, 2005).

\section{Age}

Previous laboratory based studies (Howie et al., 2012; Krähenbühl \& Blades, 2006; Warren et al., 1991) have asked whether age affects the likelihood that children will be detrimentally affected by repeated questioning. In this study, although we found that most interviews involved question repetition, the frequency with which questions were repeated declined as age increased. It was unclear why younger children were asked more repeated questions than older children but perhaps their briefer and less well-articulated responses prompted interviewers to repeat questions more often. Importantly, and unexpectedly, there was no significant relationship between age and the ways children responded to repeated questions, a result which is inconsistent with previous laboratory based studies. Nevertheless, some research suggests that, even though younger children may produce shorter and less detailed accounts of abuse (Hershkowitz, Lamb, Orbach, Katz \& Horowitz, 2012; Lamb, Sternberg, Orbach, Esplin, Stewart \& Mitchell, 2003), their reports may be no less accurate than older children's (Oates \& Shrimpton, 1991).

\section{Delay}

Similarly, the length of delay between the abuse and the interview was not associated with the reasons why questions were repeated, how interviewers asked repeated questions, or how children responded. Unlike age, delay was not associated with the frequency of question 
repetition. Longer delays can adversely affect the amount of information children provide about experiences of abuse (e.g., Lamb et al., 2000), yet, in the present study, children did not contradict themselves any more or elaborate any less on their answers when delays were longer. Some research suggests that, because traumatic experiences are personally distinctive, salient and meaningful, they may be retained better over time than memories which are less so (Fivush, Sales, Goldberg, Bahrick \& Parker, 2004; Howe, 2000; Ornstein, Gordon \& Larus, 1992). Indeed, forgetting is often extensive when neutral and positive events are recalled after long delays (e.g., Jones \& Pipe, 2002; Salmon \& Pipe, 2000).

\section{Limitations}

Unfortunately, the conclusiveness of the findings was limited by our inability to determine whether the details in the children's responses were accurate, even though there was independent corroborative evidence that all children had indeed been abused as they claimed. Furthermore, some of the small cell sizes in this study require conservative interpretations. There were also substantial discrepancies between our results and those reported by La Rooy and Lamb (2011), who found no correlation between age and the frequency with which questions were repeated. They also reported that interviewers asked repeated questions to challenge children most frequently $(62 \%)$, whereas this study revealed that questions were repeated to challenge children only $24 \%$ of the time. This inconsistency is particularly puzzling because La Rooy and Lamb (2011) analyzed interviews conducted using the Memorandum of Good Practice, which emphasizes the use of open-ended prompts and counsels against the use of suggestive interviewing techniques, whereas the interviews examined in the present study were conducted decades ago by interviewers not informed by any such guidelines, and might thus have been expected to involve more repeated questions challenging the children.

\section{Implications}


Questions may often need to be repeated in child forensic interviews to encourage children who are anxious or reluctant to disclose, to clarify questions, and to follow-up ambiguous or unclear details previously mentioned by the child. The results of this study, however, suggest that even though children of all ages were more likely to repeat or expand upon their previous answers, questions were frequently repeated for reasons other than clarification and resulted in contradictions nearly $11 \%$ of the time. Furthermore, even when questions were repeated for purposes of interviewer clarification, children were almost as likely to contradict themselves as when they were explicitly challenged, perhaps believing, in part, that the interviewers were unsatisfied with their initial answers. We therefore propose that interviewers should be given more detailed guidance concerning the appropriate use of repeated questions. Specifically, questions should only be repeated when either the children or interviewers need clarification and to encourage children who are anxious or reluctant to disclose. All repeated questions should be open-ended and when seeking clarification, interviewers should explain to children why questions are being repeated.

However, many questions remain. Future research should compare interviews conducted using specific investigative protocols. If interviews conducted using the British Memorandum of Good Practice and its successor, Achieving Best Evidence (2002, 2011) consistently challenge children as frequently as La Rooy and Lamb (2011) reported, this could signal a fundamental problem, because such questions were likely to elicit contradictions in the present study. Further, factors such as interviewer supportiveness and children's reluctance may affect both the frequency with which questions are repeated and the ways children respond. For example, contradictions may be less likely when interviewer supportiveness leads to declines in perceived social pressure. In addition, questions were sometimes repeated more than once but the current analyses focused only on questions which 
were repeated once. We do not know how repeated repetition might have affected the children's responses.

\section{Conclusion}

Overall, the present study supports findings from laboratory based research suggesting that some closed-ended question repetition can adversely affect the consistency of children's responses while open-ended question repetition can enhance children's reports. However, younger children were no more likely than older children to change their answers, despite being asked repeated questions most frequently. In addition, the length of delay seemed to have no effect on the children's responses to repeated questions. Although the repetition of option-posing and suggestive questions and those intended to challenge the child's prior answer proved problematic, there were no more adverse effects on responses to repeated questions for younger children and those who experienced longer delays compared with older children and those who experienced shorter delays. 


\section{References}

Achieving Best Evidence in Criminal Proceedings (2011). Guidance on interviewing victims and witnesses, and guidance on using special measures. London: Ministry of Justice. http://www.cps.gov.uk/publications/docsbest_evidence in_criminal_proceedings.pdf

Achieving Best Evidence in Criminal Proceedings (2002). Guidance on interviewing victims and witnesses, and guidance on using special measures. London: Ministry of Justice.

American Professional Society on the Abuse of Children, APSAC, (2012). Practice guidelines: investigative interviewing in cases of alleged child abuse. http://www.apsac.org/

Anderson, J., Ellefson, J., Lashley, J., Miller, A. L., Olinger, A., Russell, A., Stauffer, J., \& Weigman, J. (2010). The CornerHouse Forensic Interview protocol: RATAC®. Thomas M. Cooley Journal of Practical and Clinical Law, 12, 193-331.

Baddeley, A. (2007). Working memory, thought and action. Oxford: Oxford University Press.

Ceci, S. J. \& Bruck, M. (1995). Jeopardy in the courtroom: a scientific analysis of children's testimony. Washington DC: American Psychological Association.

Ceci, S. J. \& Friedman, R. D. (2000). The suggestibility of children: scientific research and legal implications. Cornell Law Review, 86, 34-108.

Endres, J., Poggenpohl, C., \& Erben, C. (1999). Repetitions, warnings and video: cognitive and motivational components in preschool children's suggestibility. Legal and Criminological Psychology, 4, 129-146. doi: 10.1348/135532599167725.

Erdelyi, M. H. (1996). The recovery of unconscious memories: Hypermnesia and reminiscence. Chicago, IL: The University of Chicago Press. 
Fivush, R., Sales, J. M., Goldberg, A., Bahrick, L., \& Parker, J. (2004). Weathering the storm: children's long-term recall of Hurricane Andrew. Memory, 12, 104-118. doi: 10.1080/09658210244000397.

Gilstrap, L. L., \& Ceci, S. J. (2005). Reconceptualizing children's suggestibility: Bidirectional and temporal properties. Child Development, 76, 40-53. doi: $10.1111 /$ j.1467-8624.2005.00828.x.

Hershkowitz, I., Lamb, M. E., Orbach, Y., Katz, C., \& Horowitz, D. (2012). The development of communicative and narrative skills among preschoolers: lessons from forensic interviews about child abuse. Child Development, 83, 611-622. doi: 10.1111/j.14678624.2011.01704.x.

Home Office (2011). Achieving the best evidence in criminal proceedings: guidance on interviewing victims and witnesses, and guidance on using special measures. http://www.cps.gov.uk/publications/docs/best_evidence_in_criminal_proceedings.pd $\underline{\mathrm{f}}$

Howe, M. L. (2000). The fate of early memories: developmental science and the retention of childhood experiences. Washington, DC: American Psychological Association.

Howie, P., Nash, L., Kurukulasuriya, N., \& Bowman, A. (2012). Children's event reports: factors affecting responses to repeated questions in vignette scenarios and event recall interviews. Journal of Developmental Psychology, 30, 550-68. doi: 10.1111/j.2044835X.2011.02064.X.

Howie, P., Kurukulasuriya, N., Nash, L., \& Marsh, A. (2009). Inconsistencies in children's recall of witnessed events: the role of age, questions format and perceived reason for question repetition. Legal and Criminological Psychology, 14, 311-329. doi: $10.1348 / 135532508 \times 383879$. 
Howie, P., Sheehan, M., Mojarrad, T., \& Wrzesinska, M. (2004). 'Undesirable' and 'desirable' shifts in children's responses to repeated questions: age differences in the effect of providing a rationale for repetition. Applied Cognitive Psychology, 18, 1161-1180. doi: 10.1002/acp.1049.

Jones, C. H. \& Pipe, M. E. (2002). How quickly do children forget events? A systematic study of children's event reports as a function of delay. Applied Cognitive Psychology, 16, 755-768. doi: 10.1002/acp.826.

Krähenbühl, S. J. \& Blades, M. (2006). The effect of question repetition within interviews on young children's eyewitness recall. Journal of Experimental Psychology, 94, 57-67. doi: 10.1016/j.jecp.2005.12.002.

Krähenbühl, S., Blades, M., \& Eiser, C. (2009). The effect of repeated questioning on children's accuracy and consistency in eyewitness testimony. Legal and Criminological Psychology, 14, 263-278. doi: 10.1348/135532508X398549.

Lamb, M. E. \& Fauchier, A. (2001). The effects of question type on self-contradictions by children in the course of forensic interviews. Applied Cognitive Psychology, 15, 483491. doi: 10.1002/acp.726.

Lamb, M. E., Hershkowitz, I., Orbach, Y., \& Esplin, P. W. (2008). Tell me what happened: structured investigative interviews of child victims and witnesses. Chichester: Wiley.

Lamb, M. E., La Rooy, D. J., Malloy, L. C., \& Katz, C. (Eds.). (2011). Children's testimony: a handbook of psychological research and forensic practice. Chichester: WileyBlackwell.

Lamb, M. E., Sternberg, K. J., \& Esplin, P. W. (2000). Effects of age and delay on the amount of information provided by alleged sex abuse victims in investigative interviews. Child Development, 71, 1586-1596. doi: 10.1111/1467-8624.00250. 
Lamb, M. E., Sternberg, K. J., Orbach, Y., Esplin, P. W., Stewart, H., \& Mitchell, S. (2003). Age differences in young children's responses to open-ended invitations in the course of forensic interviews. Journal of Consulting and Clinical Psychology, 71, 926-934. doi: 10.1037/0022-006X.71.5.926.

Landis, J. R. \& Koch, G. G. (1977). The measurement of observer agreement for categorical data. Biometrics, 33, 159-174. doi: 10.2307/2529310.

La Rooy, D. J. \& Lamb, M.E. (2011). What happens when interviews ask repeated questions in forensic interviews with children alleging abuse? Journal of Police and Criminal Psychology, 26, 20-25. doi: 10.1007/s11896-010-9069-4.

Lyon, T. D. (2002). Applying suggestibility research to the real world: the case of repeated questions. Law and Contemporary Problems, 65, 97-126. doi: 10.2307/1192367.

Lyon, T. D., Malloy, L. C., Quas, J. A., \& Talwar, V. A. (2008). Coaching, truth induction, and young maltreated children's false allegations and false denials. Child Development, 79, 914-929. doi: 10.1111/j.1467-8624.2008.01167.x.

Memon, A. \& Vartoukian, R. (1996). The effects of repeated questioning on young children's eyewitness testimony. British Journal of Developmental Psychology, 87, 403-415. doi: 10.1111/j.2044-8295.1996.tb02598.x.

Melinder, A., Scullin, M., Gavvold, T., \& Iversen, M. (2007). The stability and generalizability of young children's suggestibility over a 44-month interval. Psychology, Crime \& Law, 13, 459-468. doi: 10.1080/10683160601092997.

Oates, K. \& Shrimpton, S. (1991). Children's memories for stressful and non-stressful events. Medical Science and Law, 31, 4-10.

Ornstein, P. A., Gordon, B. N., \& Larus, D. M. (1992). Children's memory for a personally experienced event: implications for testimony. Applied Cognitive Psychology, 6, 4960. doi: 10.1002/acp.2350060103. 
Pipe, M. E., Lamb, M. E., Orbach, Y., \& Esplin, P. W. (2004). Recent research on children's testimony about experienced and witnessed events. Developmental Review, 24, 440468. doi: 10.1016/j.dr.2004.08.006.

Poole, D. A. \& White, L. T. (1991). Effects of question repetition on the eyewitness testimony of children and adults. Developmental Psychology, 27, 975-986. doi: 10.1037/0012-1649.27.6.975.

Poole, D. A. \& White, L. T. (1993). Two years later: effect of question repetition and retention interval on the eyewitness testimony of children and adults. Developmental Psychology, 29, 844-853. doi: 10.1037/0012-1649.29.5.844.

Quas, J. A., Davis, E. L., Goodman, G. S. \& Myers, J. E. B. (2007). Repeated questions, deception, and children's true and false reports of body touch. Child Maltreatment, 12, 60-67. doi: 10.1177/1077559506296141.

Salmon, K. \& Pipe, M. E. (2000). Recalling an event one year later: the impact of props, drawing and a prior interview. Applied Cognitive Psychology, 14, 99-120. doi: 10.1002/(SICI)1099-0720(200003/04)14:2<99::AID-ACP639>3.0.CO;2-5.

Scullin, M. H. \& Ceci, S. J. (2001). A suggestibility scale for children. Personality and Individual Differences, 30, 843-856. doi: 10.1016/S0191-8869(00)00077-5.

Semmler, C. \& Brewer, N. (2002). Effects of mood and emotion on juror processing and judgements. Behavioural Sciences \& the Law, 20, 423-436. doi: 10.1002/bsl.502.

Warren, A. R., Garven, S., Walker, N. E., \& Woodall, C. E. (2000). Setting the record straight: how problematic are 'typical' child sexual abuse interviews? Paper presented at the meeting of the American Psychology-Law Society, New Orleans, Louisiana.

Warren, A. R., Hulse-Trotter, K., \& Tubbs, E. C. (1991). Inducing resistance to suggestibility in children. Law and Human Behavior, 15, 273-285. doi: 10.1007/BF01061713. 
Zajac, R., Gross, J., \& Hayne, H. (2003). Asked and answered: questioning children in the courtroom. Psychiatry, Psychology and Law, 10, 199-209. doi:

10.1375/pplt.2003.10.1.199. 
Table 1

Distribution of Children across Age and Delay Categories

\begin{tabular}{lcccc}
\hline & \multicolumn{4}{c}{ Age } \\
\cline { 2 - 5 } Delay & $<6$ & $6-9$ & $>9$ & Total \\
\hline Less than 1 month & 19 & 20 & 21 & 60 \\
1 month and over & 19 & 21 & 15 & 55 \\
Total & 38 & 41 & 36 & 115 \\
\hline
\end{tabular}


Table 2

Reasons for Repetition

Code Examples

No apparent Interviewer: "How many times did this happen?" Child: "Once."

reason

Interviewer: "How many times did this happen?"

Interviewer: "Where did you go after you left the park?" Child: "To my dad's house." Later in the interview, Interviewer: "After you left the park where did you go?" [when discussing the same incident]

Challenge Interviewer: "Where did he touch you?" Child: "My back." Interviewer:

"Are you sure that is where he touched you?"

Interviewer: "What happened after you walked out of the house?" Child: "I saw my friend hit my mom." Interviewer: "Is that really what happened?"

Interviewer: "Did he do anything to your bottom?" Child: "No." Later in the interview, Interviewer: "I don't think you are telling me the truth about what he did to your bottom. Did he or did he not do something to your bottom?"

Child Interviewer: "How did he touch you?" Child: "With his hand."

clarification Interviewer: "Yes, but how did he do the touching?"

Interviewer: "What were they doing there?" Child: "Who, Daddy's friends?" Interviewer: "Yes Daddy's friends, what were they doing there?"

Interviewer Interviewer: "When did he hit you?" Child: "Last Thursday." Later in the clarification interview, Interviewer: "Um, when did you say he hit you?" [when discussing the same incident]

Interviewer: "What happened after she pulled your hair?" Child: "She did nothing and then he smacked her." Interviewer: "Okay, but I don't quite understand who did the smacking. Tell me again what happened after the hair pulling."

Interviewer: "What did it feel like?" Child: "It felt yucky." Interviewer: "I'm sorry sweetie, what did you say it felt like?" 
Digression Interviewer: "Do you know why you have come here today?" Child: "My mom said I did really well telling the police about the time D. showed me his private." Interviewer: "Yes you did very well. Do you know why you have come here today?"

Interviewer: "What did she do to your penis?" Child: "I don't want to talk about that but she hurt my bottom too." Interviewer: "Can you help me understand what she did to your penis?"

Compound Interviewer: "Were you both in the back of the car? Where were you?" Child: "In the back." Interviewer: "Where was he?"

Interviewer: "What time did K. and M. leave the house?" Child: "M. left at lunchtime." Later in the interview, Interviewer: "What about K.? What time did K. leave the house?" [when discussing the same incident] 
Table 3

Types of Interviewer Utterances

\begin{tabular}{ll}
\hline Code & Examples \\
\hline
\end{tabular}

Invitation

"Tell me everything that happened from the beginning to the end."

"Then what happened?"

"Earlier you mentioned [person/object/action]. Tell me more about that."

"Tell me everything that happened before/after you went to the park." [when 'I went to the park' was previously mentioned by the child]

Directive "Where were you when that happened?"

"Who did that to you?" [when 'that' was previously mentioned by the child]

Option-posing "Did you see his penis?"

"Was he wearing underwear?"

"Did she do that one time or more than one time?"

"Was this Thursday or Saturday evening?"

Suggestive "He forced you to do that, didn't he?"

"Your dad told me that B. touched your private part. Did B. touch your private part?"

Child: "He touched me." Interviewer: "Did he touch your pee-pee over or under your clothes?" [when the child had not previously mentioned genital touching]

Child: "He took me into the toilet." Interviewer; "When did he lock the door?" [when 'locking the door' was not previously mentioned by the child]

"Are you sure you're telling me the truth?"

"Did that really happen?" 
Table 4

Children's Responses to Repeated Questions

Code $\quad$ Examples

Elaboration Interviewer: "Where did she touch you?" Child: "She touched me on the outside of my clothes." Interviewer: "Okay, but what part of your body did she touch?" Child: "She touched me on my behind on the outside."

Repetition Interviewer: "What day did M. pick up S. from the store?" Child: "Tuesday." Later in the interview, Interviewer: "What day did S. get picked up from the store by M.?" Child: "I already told you it was Tuesday."

Contradiction Interviewer: "Did he touch you one time or more than one time?" Child: "He touched me seven times." Interviewer: "But I thought he only touched you one time. Did he only touch you one time?" Child: "He touched me one time."

Interviewer: "Did dad touch your privates at P.'s house?" Child: "Yes." Later in the interview, Interviewer: "So did dad touch your private when you were at P.'s house?" Child: "No. I didn't say that. He didn't touch me."

Digression Interviewer: "How did your private feel after the man left?" Child: "The man left really fast in his car because some big kids heard me shout but I don't want to talk about my private." Interviewer: "I know it's really hard and you're doing a great job but I really need to know if your private felt the same or different after the man left." Child: "Let's play with this dolly."

No answer Interviewer: "Did this happen over or under your clothes?" Child: "Under." Interviewer: "Are you sure it happened under your clothes?" Child: [no response].

Question Interviewer: "Did they see him do that?" Child: "My mom, B. and T." Interviewer: "Did they see him do that?" Child: "Do you mean if they saw with their eyes?" Interviewer: "Where were you when he tried to pull your pants down?" 